\title{
Quad Band H-slot Microstrip Patch Antenna for WiMAX Application
}

\author{
Swaraj Panusa \\ University College of Engineering \\ RTU, Kota (Rajasthan) India
}

\author{
Mithilesh Kumar \\ University College of Engineering \\ RTU, Kota (Rajasthan) India
}

\begin{abstract}
In this paper, a quad-band $\mathrm{H}$-slot microstrip patch antenna for WiMAX application is presented. The radiation performance such as VSWR, return loss, radiation pattern and gain of the antenna are simulated using Ansoft HFSS and presented. Radiating patch lies on the FR4_epoxy substrate which is having dielectric constant 4.1 and height $1.5 \mathrm{~mm}$. Coaxial feeding technique is used to feed the antenna with $50 \mathrm{ohm}$ impedance. This proposed antenna covers four frequency bands of $3.41-3.51 \mathrm{GHz}, 4.64-4.75 \mathrm{GHz}, 5.45-5.63 \mathrm{GHz}$ and 6.38-6.50 GHz respectively. This proposed antenna enhances the maximum return loss of $-16.92 \mathrm{~dB}$ at $3.46 \mathrm{GHz},-18 \mathrm{~dB}$ at $4.73 \mathrm{GHz},-17.50 \mathrm{~dB}$ at $5.55 \mathrm{GHz}$ and $-17.45 \mathrm{~dB}$ at $6.45 \mathrm{GHz}$ frequencies
\end{abstract}

\section{Keywords}

Patch antenna; quad-band; Radiation pattern; H-slot; VSWR; WiMAX.

\section{INTRODUCTION}

Antennas are important components in communication systems and play a role in transmitting and receiving signals. In modern wireless communication systems, multiband antenna has been playing a very important role for wireless service requirements [1]-[2]. Now-a-days, antennas with multiband capabilities have been widely required in satellite and mobile communication systems to meet the growing system complexity. With the rapid development of the modern wireless communication system, antenna design has turned to focus on wide multiband and small simple structures that can be easy to fabricate. Compact, multiband, low-profile and low-cost antennas are widely used in personal communication devices along with the rapid development of the wireless communication systems [3]-[6].

Recently, many communication standards like WiMAX etc are developed for high frequency and high speed communication. This rapid increase in communication standards has lead to a great demand for multi-band and broadband antennas with low real estate area, low cost fabrication and ease of integration with feed networks. For the past decades, the microstrip, slot, and stacked patch antennas have been used to implement multi-band [7]-[12].

In this paper, we proposed a quad band $\mathrm{H}$-slot microstrip patch antenna for WiMAX/WLAN application is presented. A coaxial probe is connected to the rectangular patch which is located close to rectangular $\mathrm{H}$-slot patch centre for good excitation of the proposed antenna over a wide bandwidth. The antenna covers four frequency bands of 3.41-3.51 GHz, 4.64-4.75 GHz, $5.45-5.63 \mathrm{GHz}$ and $6.38-6.50 \mathrm{GHz}$ respectively.

\section{ANTENNA DESIGN}

FR4_epoxy (dielectric constant $=4.1$ and height $=1.5 \mathrm{~mm}$ ) is used as substrate to design the proposed $\mathrm{H}$-slot microstrip patch antenna. The geometry of the proposed antenna is shown in Fig. 1(a) and Fig. 1(b). The dimension of the antenna is $67 \times 74 \times 1.5 \mathrm{~mm}^{3}$. To feed the proposed antenna a coaxial probe of characteristic impedance $50 \mathrm{ohm}$ is used. The antenna dimensions obtained after necessary tuning on single antenna element are shown in table 1.

Table 1. Dimensions of the proposed H-slot microstrip patch antenna

\begin{tabular}{|c|c|c|c|c|c|c|c|}
\hline Parameter & L & W & Ls & Ws & a & b & $y_{f}$ \\
\hline $\begin{array}{c}\text { Units } \\
(\mathrm{mm})\end{array}$ & 33.5 & 23 & 28 & 15 & 2.5 & 3 & 3.25 \\
\hline
\end{tabular}

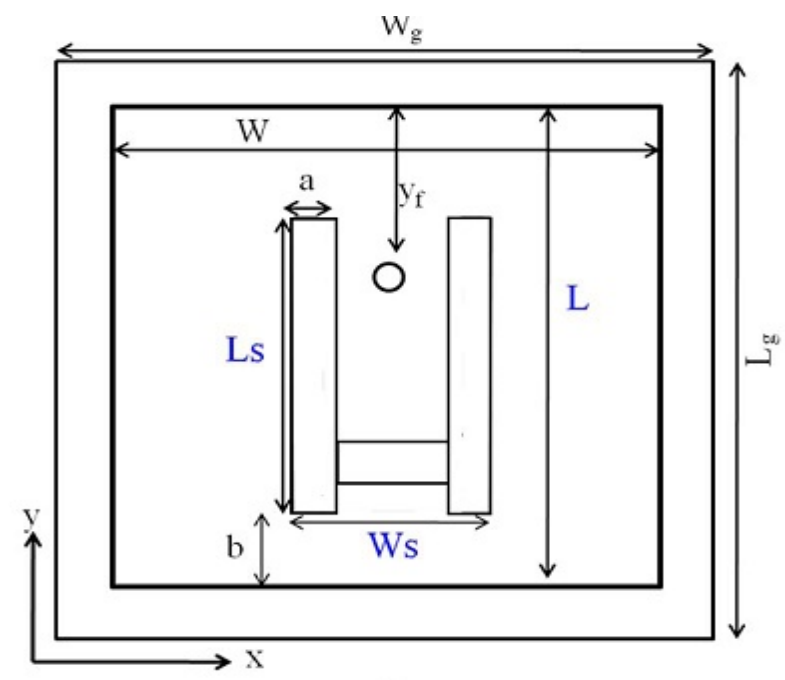

(a)

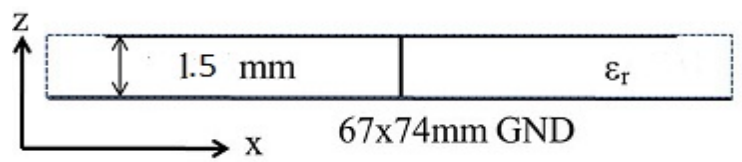

(b)

Fig 1: Geometry of the proposed H-slot microstrip antenna: (a) top view (b) side view 


\section{SIMULATED RESULTS}

In this section, simulation is done for the proposed multi-band H-slot microstrip patch antenna by Ansoft HFSS. The proposed antenna have impedance matching better than -10 $\mathrm{dB}$ return loss for frequency range of $3.41-3.51 \mathrm{GHz}, 4.64-$ 4.75 GHz, 5.45-5.63 GHz and 6.38-6.50 GHz respectively. Fig. 2 shows the current distribution in the patch of the proposed antenna. Fig. 3 shows that the antenna have the maximum return loss of $-16.92 \mathrm{~dB}$ at $3.46 \mathrm{GHz},-18 \mathrm{~dB}$ at $4.73 \mathrm{GHz},-17.50 \mathrm{~dB}$ at $5.55 \mathrm{GHz}$ and $-17.45 \mathrm{~dB}$ at $6.45 \mathrm{GHz}$. Fig. 4 shows the VSWR value lesser than 2 for the frequency range of $3.41-3.51 \mathrm{GHz}, 4.64-4.75 \mathrm{GHz}, 5.45-5.63 \mathrm{GHz}$ and 6.38-6.50 GHz respectively. Fig. 5 shows the simulated 2D radiation pattern at $3.46 \mathrm{GHz}, 4.73 \mathrm{GHz}, 5.55 \mathrm{GHz}$ and 6.45 $\mathrm{GHz}$ frequency respectively.

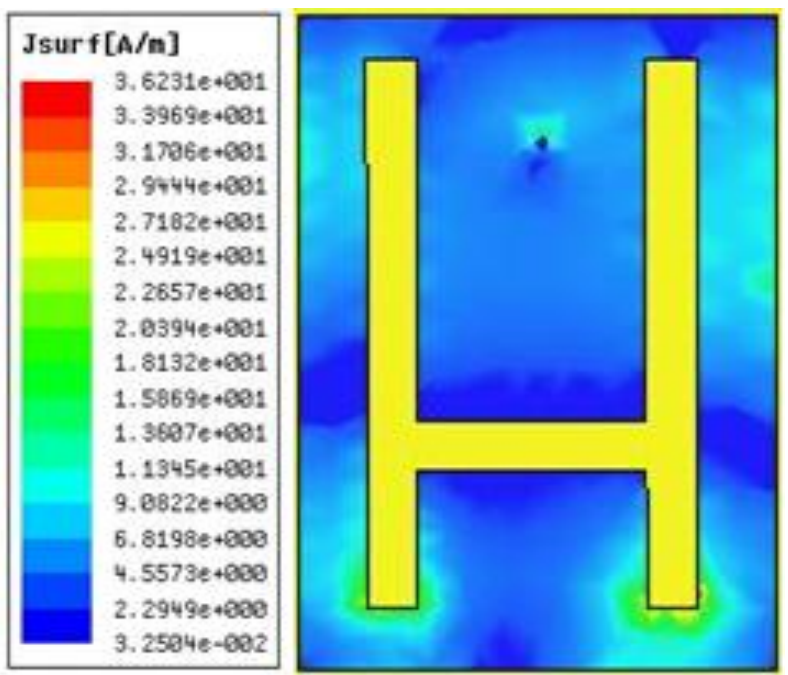

Fig 2: Current distribution in the patch of the proposed antenna

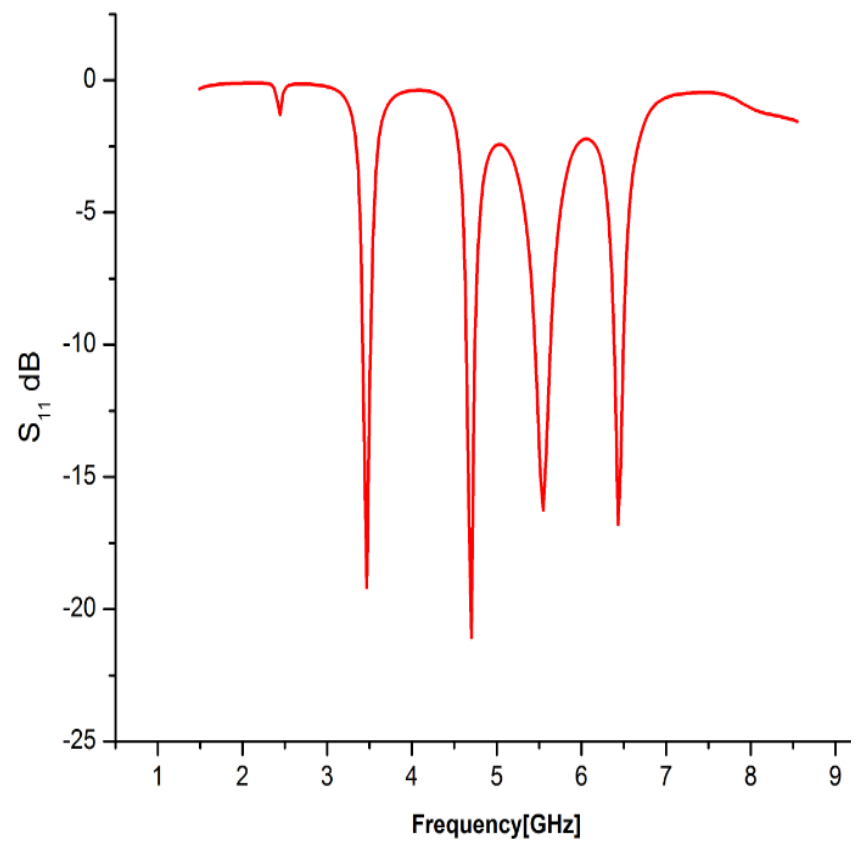

Fig 3: Simulated return-loss of the proposed Hslot microstrip patch antenna

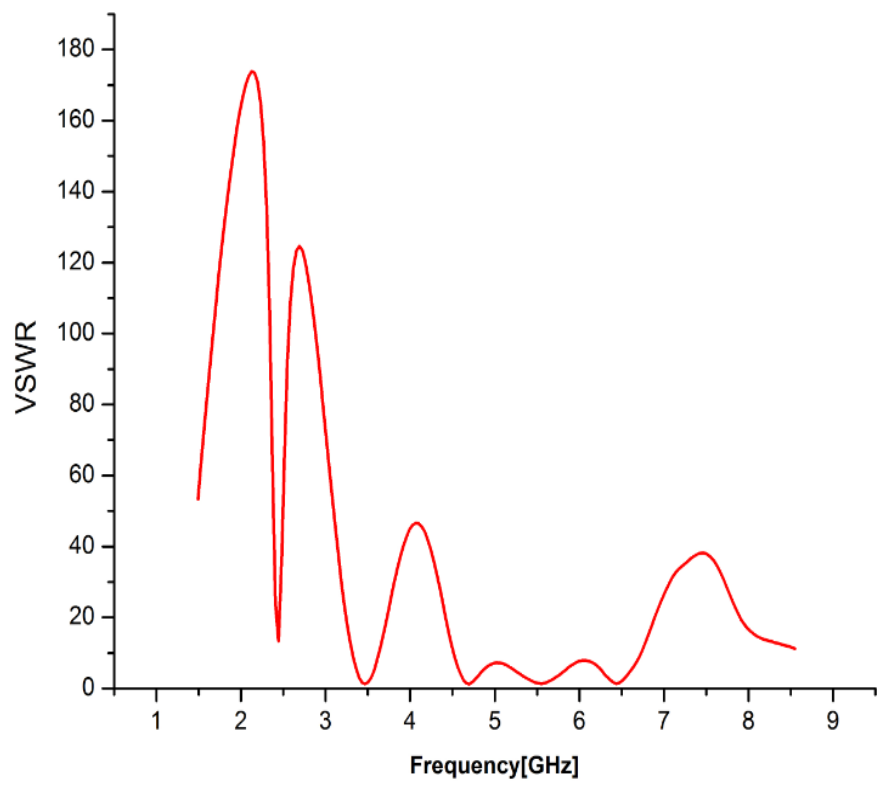

Fig 4: Simulated VSWR plot of the proposed antenna

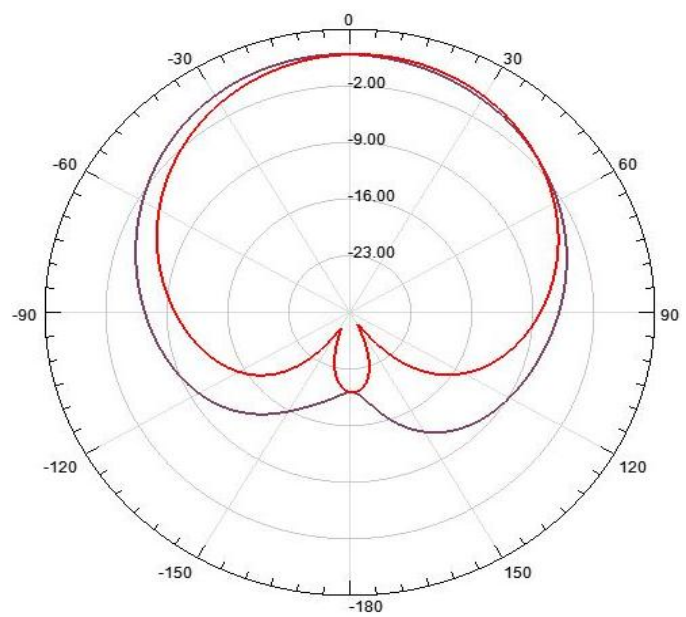

(a)

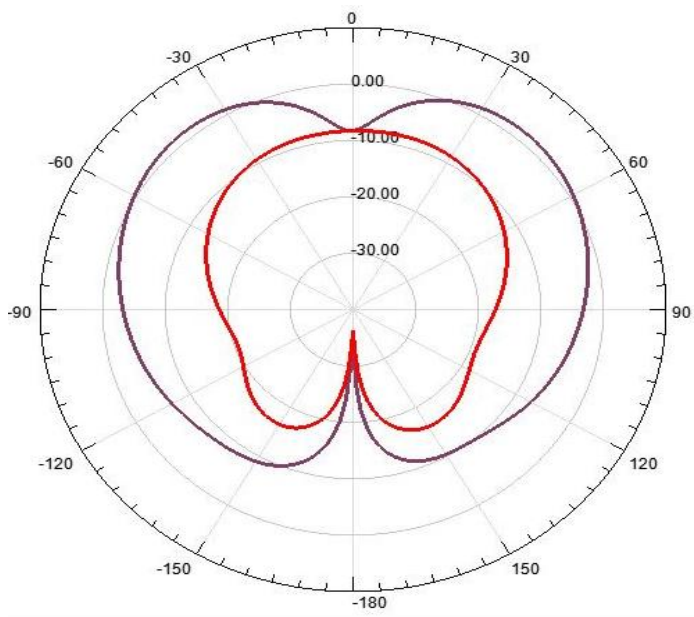

(b) 


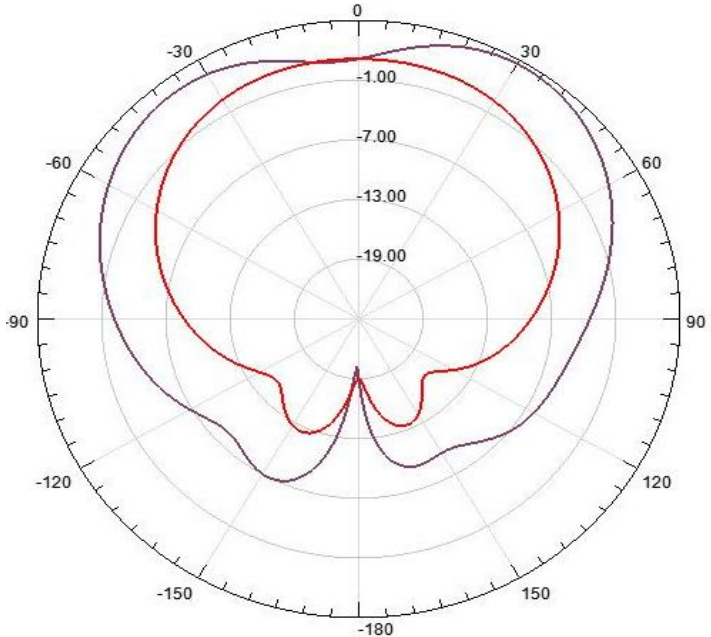

(c)

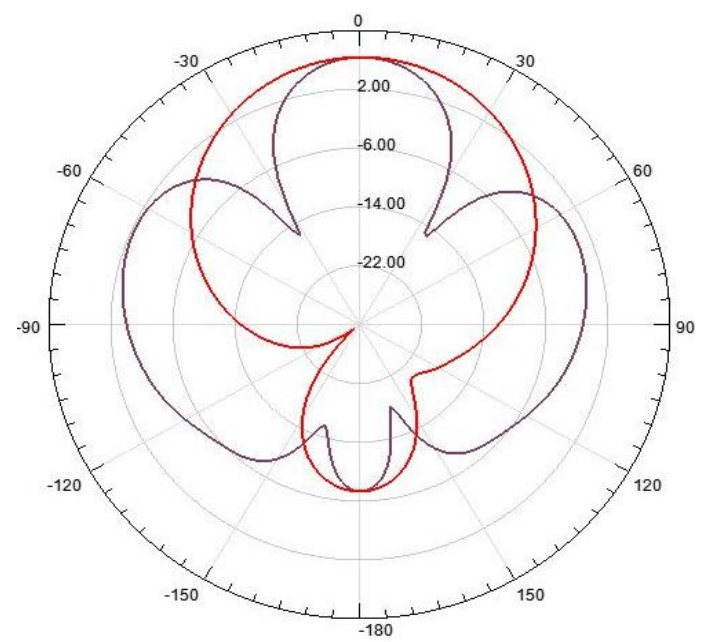

(d)

Fig 5: Simulated radiation pattern of the proposed antenna at (a)3.46 GHz (b)4.73 GHz (c)5.55 GHz (d)6.45 GHz

\section{CONCLUSION}

In this paper a quad band $\mathrm{H}$-slot antenna for WiMAX/WLAN applications is proposed and analyzed through different parametric studies using Ansoft HFSS simulation software. Compared to many antennas proposed earlier, this antenna is designed based on a rather simple structure. The proposed antenna can be considered to achieve multiband just through etching $\mathrm{H}$-slots on the patch, so it can be much easier to fabricate. The proposed antenna have achieved good impedance matching, stable radiation pattern and satisfied return loss. The measured results show that the obtained impedance bandwidths are from 3.41-3.51 GHz, 4.64-4.75 $\mathrm{GHz}, 5.45-5.63 \mathrm{GHz}$ and $6.38-6.50 \mathrm{GHz}$ respectively, good enough for WLAN and WiMAX applications. In addition, the proposed antenna has good radiation characteristics and gains in the three operating bands, so it can emerge as an excellent candidate for multiband generation of wireless.

\section{REFERENCES}

[1] Hari Shankar Singh, Mayank Agarwal, Gaurav Kumar Pande, and Manoj Kumar Meshram, "A Quad Band Compact Diversity Antenna for GPSL1/WiFi/LTE2500 /WiMAX/HIPERLAN1 Applications," IEEE Antennas and Wireless Propagation Letters, Vol. 13, 2014

[2] Ahmed Khidre, Kai-Fong Lee, Atef Z. Elsherbeni, and Fan Yang Wide Band Dual-Beam U-Slot Microstrip Antenna; IEEE Transactions On Antennas And Propagation, Vol. 61, No. 3, March 2013.

[3] Sana Arif, Syeda Areeba Nasir, Muhammad Mustaqim and Bilal A. Khawaja, Dual U-Slot Triple Band Microstrip Patch Antenna for Next Generation Wireless Networks , PNEC, NÜST, Karachi, SNS \& PCS, 2013.

[4] Muhsin Ali and Bilal A. Khawaja, Dual Band Microstrip Patch Antenna Array for Next Generation Wireless Sensor Network Applications. PNEC, NUST, International Conference on Sensor Network Security Technology and Privacy Communication System (SNS \& PCS), 2013.

[5] Wang Ren, "Compact H-Shaped Slot Antenna for 2.4/5.8GHz WLAN Applications," IEEE International Conference on Multimedia Technology (ICMT), 2010.

[6] Ebrahim Sailan Aabidi, M. R. Kamarudin, T. A. Rahman, and Hashimu Uledi Iddi, "Multi-band Circular Patch Antenna for Wideband Application,"Wireless Communication Centre (WCC), Universiti Teknologi Malaysia UTM Skudai, Johor 81310, Malaysia, PIERS Proceedings, Stockholm, Sweden, Aug. 12-15, 2013.

[7] K. Li, M. Ingram, and E. Rausch, "Multibeam antennas for indoor wireless communications," IEEE Trans. Comm., vol. 50, no. 2, Feb. 2002.

[8] K. F. Lee, K. M. Luk, K. M. Mak and S. L. S. Yang "On the use of U-slots in the design of dual and triple band patch antennas", IEEE Transactions on Antennas and Propagation.

[9] Tze-Hsuan Chang and Jean-Fu Kiang, Compact MultiBand H-Shaped Slot Antenna, IEEE Transactions on Antennas and Propagation, volume 6, issue 8, 2013.

[10] Y.-F. Lin, P.-C. Liao, P.-S. Cheng, H.-M. Chen, C.T.P. Song and P.S.Hall, CPW-fed capacitive $\mathrm{H}$-shaped narrow slot antenna, Electronics Letters Vol. 41 No. 17, 18th August 2005.

[11] Aleš ČÁP, Zbyněk RAIDA, Eduardo de las HERAS PALMERO, Roberto lamadrid ruiz,"Multi-Band Planar Antennas: A Comparative Study, " Radio Engineering, Vol. 14, No. 4, December 2005.

[12] Wang Ren, Compact H-Shaped Slot Antenna for 2.4/5.8GHz WLAN Applications, IEEE International Conference on Multimedia Technology (ICMT), 2010.

[13] J C. A. Balanis, Antenna Theory Analysis and Design, 2nd ed. Hoboken, NJ, USA: Wiley-Interscience, 2005.

[14] Ansoft HFSS ver. 13, Ansoft Corporation. Canonsburg, PA, USA. 